\title{
Carnets
}

Revue électronique d'études françaises de l'APEF

Première Série - 1 Numéro Spécial | 2009

Cultures littéraires : nouvelles performances \& développement

\section{Cultura, literatura, identidade e a construção de ideais nacionais}

João Carlos Firmino Andrade de Carvalho

\section{(2) OpenEdition}

Journals

Édition électronique

URL : http://journals.openedition.org/carnets/3540

DOI : $10.4000 /$ carnets.3540

ISSN : 1646-7698

Éditeur

APEF

Édition imprimée

Date de publication : 1 juin 2009

Pagination : 81-90

Référence électronique

João Carlos Firmino Andrade de Carvalho, «Cultura, literatura, identidade e a construção de ideais nacionais ", Carnets [En ligne], Première Série - 1 Numéro Spécial | 2009, mis en ligne le 16 juin 2018, consulté le 01 mai 2019. URL : http://journals.openedition.org/carnets/3540 ; DOI : 10.4000/ carnets.3540

Carnets est mis à disposition selon les termes de la licence Creative Commons - Atribution - Pas d'utilisation commerciale 4.0 International. 


\title{
CULTURA, LITERATURA, IDENTIDADE E A CONSTRUÇÃO DE IDEAIS NACIONAIS
}

\author{
JoÃo CARLOS FIRMINO ANDRADE DE CARVALHO \\ FCHS e CELL ${ }^{1}$, Universidade do Algarve \\ jccarva@ualg.pt
}

\begin{abstract}
Résumé
Nous proposons ici une réflexion autour de l'histoire de la culture et de la littérature portugaises, en retenant quelques apports de poètes, écrivains, intellectuels à la construction des idéaux mobilisateurs de la société portugaise (et pas seulement): de la conscience critique et de l'idéal d'héroïcité de Camões, du Cinquième Empire et d'António Vieira, du Saudosismo universel de Pascoais, de l'Integralismo Lusitano de A. Sardinha (et les rapports avec la droite française de Maurras), jusqu'à la Patrie Universelle et le Modernisme de Pessoa ou même jusqu'à la vision d'un Saramago ou, encore, d'un Eduardo Lourenço. Tous ces exemples nous donnent à voir qu'il n'y a pas de future sans une lecture du passé qui nous permette de regarder plus loin. De la première "globalisation" du temps des Découvertes Portugaises jusqu'au plus récent Portugal européen et à l'époque de la globalisation de nos jours, se pose l'importante question des identités culturelles.
\end{abstract}

\begin{abstract}
We propose here to reflect about Portuguese cultural and literary history, holding back some contributions of poets, writers, intellectuals to the construction of mobilizing ideals of Portuguese society (and not only): from the critical conscience and the ideal of heroism of Camões, passing through the "Quinto Império" and António Vieira, by the universalistic "Saudosismo" of Pascoais, the "lintegralismo Lusitano" of António Sardinha (and its relations with the political French movement of Charles Maurras), until the "Pátria Universal" and the Modernism of Pessoa or still until the vision of Saramago or even Eduardo Lourenço. All have showed us that there is no future without a reading of the past that makes us to see further. From the first "globalization" in the time of the Portuguese Discovery to the recent European Portugal and the Age of the total globalization of our days, an important question emerges: the question of cultural identities.
\end{abstract}

Mots-clés: Culture, Littérature, Identité, Idéaux, Nationalités

Keywords: Culture, Literature, Identity, Ideals, Nationalities

\footnotetext{
${ }^{1}$ Centro de Estudos Linguísticos e Literários da Universidade do Algarve (financiado pela FCT) - Linha de Investigação intitulada Estudos Literários e Comparados - Tarefa 1: "Identidades e Diferenças Europeias e ExtraEuropeias no Plano Literário e Cultural".
} 
A temática deste Fórum APEF 2008, dedicada à questão das Culturas Literárias novas performances e desenvolvimento, impele-me a vir aqui partilhar convosco algumas reflexões e inquietações que julgo não vos serem estranhas. O ponto de vista adoptado aqui não é o do criador cultural ou literário, nem mesmo o do crítico literário, mas mais o do docente de cultura e de literatura na universidade portuguesa. O tom inicial e final não será o do pessimista militante ou do optimista ingénuo, mas construtivamente crítico, porventura desafiador. Falar do estado das culturas literárias é falar da cultura na nova complexidade hodierna, é falar das visões de certas elites culturais, mas é também falar da crise das humanidades, no contexto português e não só. No mundo neoliberal e global de hoje, sabemo-lo bem, os saberes culturais tradicionais da área das humanidades perderam terreno na sua relação com o(s) Poder(eres) e foram obrigados a um lifting pragmatizador (a cultura literária serve para quê?) e a uma avaliação diligente na perspectiva da grelha importada das ciências ditas não-humanas. Sobrevivem acantonados em nichos da alta cultura, adaptam-se aos novos tempos aceitando as novas regras do jogo, ou então definham e morrem, sendo substituídos por discursos do âmbito da chamada cultura de massas (onde agora parece habitar a cultura popular) ou substituídos ainda por saberes artísticos ou culturais não especializados. Vivemos uma época complexa e exigente em que o diálogo entre os saberes não deveria implicar a perda de especificidade (especialização) desses mesmos saberes culturais. E isso é válido para as Ciências Duras, mas também para as Ciências Históricas e Humanas.

Não é minha intenção falar dos saberes na universidade, mas antes do estado das culturas literárias no âmbito das Humanidades, partindo da constatação de que o lugar, a especificidade, bem como a eficácia de tais saberes se tornaram, no mínimo, problemáticos, tornando-se evidente que há aqui muito para, primeiramente, reflectir, para, depois, passar ao tempo de fazer agir os protagonistas que somos todos nós. É que, creio estarmos todos de acordo, a Cultura (humanística e literária incluídas, para além da científica) é uma parte importante na construção de visões e de ideais para o futuro das sociedades. O futuro não se constrói olhando passivamente para o passado, mas também não se constrói sem o conhecimento desse mesmo passado. A amnésia cultural é uma forma de ignorância, cujas consequências são bem conhecidas. Claro que aquilo que chamamos de cultura portuguesa ou francesa ou alemã, ou seja, as identidades históricas europeias, nascem com a construção romântica da Nação como habitáculo do cultural identitário. Sabemos como ideológica e politicamente isso foi utilizado. Mas não devemos esquecer que, apesar da mitologização romântica, por um lado, o cultural vem antes do político, e, por outro, esse cultural não se deixa fixar em fronteiras geográficas definidas (daí a importância das abordagens comparatistas). 
Permitam-me que vos convide a olharmos para a nossa história da cultura e da literatura para recordar alguns contributos interessantes de poetas, escritores, intelectuais, homens de cultura, para a tal construção de ideais mobilizadores da sociedade portuguesa (e não só), de projectos nacionais (e universais), independentemente da maior ou menor empatia que eles possam suscitar aos olhos de hoje.

Não por acaso, o nosso século XVI serve-nos como primeiro excelente exemplo do contributo que poetas e escritores, como Luís de Camões (1524?-1580) e Fernão Mendes Pinto (c.1510-1583), deram para a construção de ideais individuais e colectivos (nacionais e universais), incorporando neles uma consciência crítica. De facto, é bastante redutora aquela estafada oposição entre estes dois autores assente na contraposição entre a euforia épica colectiva e a narrativa autobiográfica disfórica. Em ambas, há a euforia da ideologia dominante (da dilatação da fé e do império) e a disforia da crítica dos Descobrimentos portugueses. No século XVI, a religião constitui o verdadeiro "bilhete de identidade" individual e colectivo. Ora Fernão Mendes Pinto, na sua Peregrinação (1614; cf. Pinto, 1995), dá-nos conta dessa referência identitária cristã absolutamente essencial, à qual nunca renegará (a surpreendente e fantástica China seria perfeita se fosse cristã, diz ele), pois não é por acaso que regressará ao seu país como cristão e aqui constituirá família (enquanto outros optaram por ficar por diferentes paragens do Oriente e Extremo-Oriente, adoptando, nalguns casos inclusive, outros costumes e outras religiões). Isso não o impedirá de mostrar uma atitude muito crítica em relação a certas práticas do CristianismoCatolicismo ou em relação à corrupção, à cobiça e a certa forma desleixada ou incompetente de administração do Império no Oriente. N' Os Lusíadas de Camões (1572; cf. Camões, s/d), encontramos, como é sabido, a exaltação do herói colectivo (os Portugueses) e individual (Vasco da Gama), mas o ideal de heroísmo camoniano, que articula as características do herói medieval (a do corajoso guerreiro) com as características do novo herói da Renascença (a do herói culto, humanista), encontra fraco eco na sua narrativa épica. Vasco da Gama, se consegue o que consegue, foi porque os Deuses lho permitiram. A recompensa oferecida aos Portugueses é posta no plano da pura ficção (a llha dos Amores, onde os homens se tornam deuses e os deuses se tornam homens; a Contemplação da Máquina do Mundo). Ora, numa epopeia, que quebra os códigos do género ao atribuir tanta importância à verdade histórica (a rememoração de figuras e factos exactos da História de Portugal até ao presente é uma marca de inovação), bem como à verdade experiencial (o "vi claramente visto"), este herói individual surge de forma apagada e a recompensa aos nautas surge como sublimação poética alternativa (assentando bem no tradicional género épico, mas quebrando a verdade factual que, eventualmente, seria suposta continuar). Se, no final da Peregrinação, Fernão Mendes Pinto se mostra reconhecido ao seu Deus cristão e agradecido pelas suas longas e fantásticas experiências 
peregrinantes, não deixa de se mostrar céptico em relação ao Homem. Por seu turno, Camões, no final da sua epopeia, mostra todo o seu cepticismo e desilusão em relação aos Portugueses $^{2}$ por não encaixarem perfeitamente no seu modelo de heroicidade idealizado e que, por isso mesmo, se torna um modelo por cumprir (daí o sentido didáctico do seu Poema). Acrescente-se, no entanto, que tal cepticismo também surge compensado pelo optimismo da Fé cristã. Em conclusão, por vias diferentes de escrita, embora complementares, Fernão Mendes Pinto e Camões dão-nos a ver ideais individuais e colectivos do Portugal Quinhentista. Camões fá-lo, inserindo-se numa erudita tradição clássica (embora o faça para a superar), olhando para o Passado e para o Futuro; Fernão Mendes Pinto, não tão eruditamente, também o faz, vivenciando o seu presente e experimentando uma escrita que, embora tenha raízes bem sedimentadas, de certo modo contribuirá para o nascimento do género romance, o qual, como é sabido, só surgirá a partir do século XVIII, com ajuda dos franceses.

O final traumático do século XVI - o desaparecimento de D. Sebastião em AlcácerQuibir, a perda da independência para a Espanha, o desmoronar do império português favorecerá o profetismo messiânico que terá as Trovas quinhentistas de inspiração bíblica do Bandarra, sapateiro de Trancoso, como referência basilar.

No século XVII, o génio da oratória barroca portuguesa - Padre António Vieira - fará a transposição de tal profetismo messiânico para esse Novo Mundo que é o Brasil, aproveitando uma hermenêutica antropológica que lê o Índio brasílico enquanto habitante adâmico do novo paraíso, hermenêutica essa que recua aos tempos da Carta do Achamento do Brasil (1500) do escrivão Caminha e estará presente ao longo de todo o século XVI (veja-se a particular importância atribuída não apenas ao ensino do português aos índios, mas também o interesse dos Padres jesuítas e franciscanos pelo conhecimento das línguas nativas como o Tupi ${ }^{3}$, num verdadeiro trabalho tradutivo e comparatista, com vista a uma mais eficaz evangelização desse povo indígena eleito de Deus). A utopia do Quinto Império ou Império de Cristo ou ainda Império do Espírito Santo, em Padre António Vieira, centrar-se-á, agora, no cenário brasileiro e no índio imaculado pelo pecado original e, por isso mesmo, o cristão do futuro, surgindo assim, Brasil e Índios, como um prolongamento de Portugal e dos Portugueses num além utópico e espiritual. A sua obra Esperanças de Portugal, Quinto Império do Mundo, porventura um esboço da sua História do Futuro publicada já nos inícios do século XVIII, e que lhe valeu a perseguição do Santo Ofício, insere-o, claramente, no pensamento milenarista de um Joaquim de Flora e, por essa

\footnotetext{
2 "No mais, Musa, no mais, que a Lira tenho/ Destemperada e a voz enrouquecida,/ E não do canto, mas de ver que venho/ Cantar a gente surda e endurecida./ O favor com que mais se acende o engenho/ Não no dá a pátria, não, que está metida/ No gosto da cobiça e na rudeza/ Dhũa austera, apagada e vil tristeza.", Canto X, estância 145, (Camões, s/d: 351).

${ }^{3}$ José de Anchieta, Arte de Gramática da Língua mais usada na Costa do Brasil, Coimbra, 1595. Outro gramático, Pêro de Magalhães de Gândavo, escreverá a primeira História do Brasil (cf. Gândavo, 1984).
} 
via, na tradição messiânica hebraica. A utopia do Quinto Império invadirá o pensamento filosófico, político e estético português como tema, mito ou metáfora, e terá, no século $X X$, um arauto bem conhecido de todos - Fernando Pessoa - apesar de, logo no século XVII, e sobretudo no século XVIII, ter tido opositores ferozes (o Marquês de Pombal à cabeça, mas além dele, evidentemente, todo o pensamento iluminista e neoclássico de Setecentos e, principalmente, os vários racionalismos até ao século XX).

É bem sabido que o conceito de cultura como lugar coerente da memória de um povo, de uma nação, é filho do pensamento romântico, obcecado com a demanda e estudo das origens, do passado ordenado, visando a legitimação das nacionalidades europeias. Foi assim na Alemanha do Sturm und Drang e de Herder, Goethe e Schiller, na Inglaterra de Wordsworth e Coleridge, na Escócia de James Macpherson ${ }^{4}$, na França de Victor Hugo e Lamartine, e, também, no Portugal, de Bocage, Alexandre Herculano e Almeida Garrett. $O$ século XIX serviu-nos uma História de Portugal (como da França, da Inglaterra ou da Alemanha) apaixonante, vibrante, misteriosa, e ordenada segundo uma lógica interpretativa que, naturalmente, está ao serviço dos interesses diversos deste período histórico específico e que muito se devem à justificação da identidade nacional. Costuma dizer-se, e com razão, que quem quer estudar a fundo uma qualquer temporalidade anterior ao século XIX terá, necessariamente, que romper o véu romântico que cobre o passado (a preferência romântica pela idade de ouro medieval, pelos pares amorosos como Pedro e Inês, pelos mitos como o das origens da nacionalidade, o da Saudade, o do Encoberto, ou o do Camões de Garrett, a leitura do Cancioneiro tradicional, e compreender, quer certa empatia para com o excesso barroco, quer a antipatia pelo século XVIII).

Entre ideais ora de pendor mais racionalizante e aberto a correntes do pensamento europeu ora de pendor mais ensimesmado na alma nacional, entramos agora no século XX, antes de terminar esta deambulação.

Gostaria de me referir agora a uma corrente de pensamento que me parece insuficientemente conhecida pelas gerações mais novas: refiro-me ao Integralismo Lusitano $^{5}$. Esta corrente nasce com a insurreição monárquica liderada por Paiva Couceiro (1911-1912), tendo os seus seguidores confluído para o exílio, em redor da revista Alma Portuguesa (1913) e, mais tarde, em torno da revista Nação Portuguesa, nascida em Coimbra, em 1914. Será depois liderada, em 1916, pela figura preponderante de António Sardinha (1887-1925), responsável pela então chamada Junta Central. Apesar das origens paradoxalmente republicanas e anarco-sindicalistas, esta corrente, desencantada com a

\footnotetext{
${ }^{4}$ Cf. a questão da invenção da figura do poeta celta Ossian ou da falsificação da história literária (i.e., referimonos à suposta recolha de lendas e poemas épicos gaélicos antigos que atestaria a primazia da cultura escocesa sobre a inglesa e as outras nacionalidades). Ossian tornar-se-á mesmo o Homero do jovem Werther...

${ }^{5}$ Cf. Catroga e Carvalho (1996), assim como Coelho (dir., 1997).
} 
República, tornar-se-á anti-democrática. Curiosamente, esta corrente tem origens estéticas e literárias (os Esotéricos), e os seus membros consideravam-se iniciados de um culto e distantes da massa estudantil da Coimbra de então. Almada Negreiros, entre outros, também andou por aqui... Programaticamente, o Integralismo defendia a restauração da Monarquia tradicionalista e anti-parlamentar, centrada na figura toda-poderosa do Monarca (embora não absolutista!), bem como a defesa dos privilégios da religião católica, apostólica e romana. A revista Nação Portuguesa agitava as elites sócio-económicas e intelectuais de forma a que estas pusessem em acção a reforma do Estado. O Integralismo buscava a mítica alma nacional num Estado que finalmente reencontrasse a Nação imortalizada pela História e que se teria perdido com o Liberalismo e com a República. E nisto estão muito próximos da direita francesa da mesma época (a Action Française de Charles Maurras, Paris, 1908). Reaportuguesar Portugal é a sua utopia regressiva que visava a restauração da legitimidade cristã e monárquica, aproximando-se, de certo modo, do ideário fascista que se começará a formar na Europa. É que o Integralismo não é apenas uma corrente de pensamento conservador; é muito mais um movimento de acção política com fins violentos e totalitários, assente nessa articulação entre tradição e inovação, passado e futuro. E não tendo chegado a ser um movimento de massas, não deixou de ter influência em certa intelectualidade de então (António Ferro andou por aqui...), embora Salazar o tivesse ignorado. Mas os Integralistas oporão aos seus congéneres franceses da época, que defendiam a tese da Latinidade para depois expressar a supremacia francesa no mundo, a tese da Hispanidade, que considerava a Península Ibérica como a essência da civilização cristã ocidental. Todavia, eram anti-iberistas, pois defendiam a unidade espiritual, mas não política. O conceito de nacionalidade assenta aqui nos semas da profundidade (i.e., ancestralidade espiritual), tradicionalismo (i.e., unidade rácica e religiosa), rusticidade (i.e., a alma da nação está na terra), organicidade (i.e., a nação funciona como um organismo vivo). O Integralismo assume-se como anti-capitalista, anti-judaico, anti-protestante e antimaquinismo italiano, embora muito compreensivo para com o Salazarismo.

Passemos a outro exemplo. Teixeira de Pascoais (1877-1952) é conhecido por ter criado o movimento estético-filosófico de carácter panteísta e nacionalista opositor do racionalismo e positivismo da Geração de 70. Com Jaime Cortesão, Leonardo Coimbra e Augusto Casimiro funda o chamado grupo da Renascença Portuguesa e a revista portuense A Águia (1910-1930). É a Pascoais que se deve a corrente mística que busca o âmago da alma lusitana, conhecida por doutrina do Saudosismo. Defende a ideia "romântica" da articulação íntima do Saudosismo com o Republicanismo à portuguesa, ou seja, nãoconstitucionalista como a francesa. Recusa a sociedade urbana e industrial e faz a apologia da rusticidade e de uma Igreja Lusitana, pois o povo português é, para ele, muito religioso, mas não católico. O Saudosismo de Pascoais é idiossincrasia portuguesa, mas pretende ser 
de realização universal. A sua visão poética e filosófica é de filiação sebastianista, messiânica, (D. Sebastião é Cristo redentor), mas não partilha propriamente dos ideais do Quinto Império dos intelectuais antidemocráticos e anti-republicanos. A Saudade não é, como será para António Sérgio, algo de estático e de retrógrado, mas desejo de futuro aliado à lembrança do passado. Na Arte de Ser Português (1915; cf. Pascoais, 1991), o seu Saudosismo parte de um levantamento antropológico-cultural para chegar às ideias de Raça e de Pátria como algo de espiritual e universal. Para ele, existiria um destino português, uma maneira de ser lusitana que assenta numa energia virada para um futuro de liberdade, numa espécie de superação hegeliana espiritual e não materialista (diferente portanto do materialismo-idealismo de Antero de Quental).

Tal como Pascoais, também Fernando Pessoa (1888-1935) se insere na linha da superação idealista do positivismo. A poesia é ascese ao estado puro da criação, ao universal. Por isso, a apologia da especificidade nacional não significa ensimesmamento, mas antes consciência planetária. O Modernismo, de facto, não se deixa enclausurar numa estreita visão nacionalista. Aliás, o Modernismo terá uma relação conflituosa com o nacionalismo político, quer o do Integralismo Lusitano de António Sardinha, quer o de António Ferro (seu ex-companheiro do Orpheu de 1915) e de Oliveira Salazar. Pessoa assume-se como intérprete de uma cultura nacional de forma desconcertante: "Uma literatura original, tipicamente portuguesa, não o pode ser porque os portugueses típicos nunca são portugueses" (Pessoa, 1986: 84). Pessoa não se deixa catalogar em nenhuma corrente estético-filosófica ou política (monárquicos, republicanos, fascistas italianos, igreja, sindicatos ou associações), a não ser, e mesmo assim de uma forma muito peculiar, no Modernismo universalista. O Orpheu de Pessoa postulava uma arte cosmopolita no tempo e no espaço (intersecção do misticismo asiático, do primitivismo africano, do cosmopolitismo americano, do exotismo da Oceânia e ainda do maquinismo decadente da Europa). A arte moderna, a seu ver, afirma-se desnacionalizada e enquanto o lugar de todas as artes. Assim, a Cultura portuguesa será tanto ou mais portuguesa quanto mais desnacionalizada, universal, ela for. O Futurismo de teor guerreiro e apocalíptico à maneira dos italianos e de Marinetti é algo que caracteriza muito mais Almada Negreiros do que Pessoa. O seu SuperCamões não corresponde ao Homem Definitivo de Almada Negreiros. O herói pessoano é ecuménico e sensível, não é o vencedor agressivo, nem o nacionalista. Pessoa não partilhará da visão do Quinto Império Sebastianista do Sidonismo (como alguns modernistas desencantados). O seu Quinto Império é imaterial e não físico, e está longe da perspectiva da Igreja romana. Pessoa está de facto mais próximo do Saudosismo universal de Pascoais do que do Catolicismo nacionalista. O seu Quinto Império é o da Poesia, o da Palavra, o da Língua Portuguesa (como para Camões e para António Vieira, aliás). Desde Camões até Pessoa e o Modernismo existe, podemos dizê-lo, uma consciência da decadência inexorável 
do império português e da necessidade de afirmação da língua e cultura portuguesas no mundo. Talvez agora se torne mais clara a sua afeição pela Maçonaria, sociedade secreta que postula a defesa da fraternidade universal contra a exploração do Homem. A Poesia, a Cultura, surgem como a única forma de redenção do Homem guiado pelas elites culturais, num mundo e numa época de extermínio do Outro, de extrema violência e agressividade. Pessoa também não era propriamente um democrata (era mais um liberal à inglesa), pois considerava que a liberdade das massas é uma ilusão, mas acreditava na libertação individual e na do povo bem guiado pela elite certa.

Os exemplos históricos que acabei de apresentar mostram-nos visões e projectos de futuro, em termos de nacionalidade e identidade. Muitos outros poderiam ser aqui trazidos, como o caso do único escritor português que ganhou o Prémio Nobel da Literatura, José Saramago, cuja interpretação ficcional da História de Portugal desconstrói, num registo pósmoderno, a historiografia oficial ${ }^{6}$ (pondo em destaque a heroicidade dos fracos, oprimidos ou anónimos). Saramago revê e reinventa os temas e os mitos da cultura portuguesa e ocidental (veja-se a sua visão crítica do país da era europeísta, apostando num destino ibérico comum a Portugal e Espanha ${ }^{7}$; veja-se a sua reinvenção do universo pessoano ${ }^{8}$ ou do tema do cristianismo ${ }^{9}$ ). Do romance histórico pós-moderno, num estilo oral, barroquista, brusco e paródico, Saramago passará, numa fase mais recente, para uma abordagem céptica da condição humana e do indivíduo na era da globalização que tudo anula (valores, diferenças e liberdades), num estilo mais sóbrio e pragmático ${ }^{10}$.

Gostaria de terminar, cotejando o pensamento de Eduardo Lourenço (cf. Silva e Jorge, 1993). De facto, esta nossa mania muito portuguesa (e que surpreende muitos estrangeiros, embora, na verdade, não detenhamos a exclusividade) de andarmos sempre em torno do nosso umbigo, na tentativa nunca acabada de definirmos a nossa identidade, parece ser um sintoma de uma hiper-identidade, resultante do nosso défice identitário real que é compensado pelo imaginário simbólico nacional e pelos mitos fundadores e históricos. As identidades locais acabam por ser mais fortes do que uma identidade unitária (os antropólogos sabem-no bem). Isso dever-se-ia ao seu acentrismo, defende Boaventura Sousa Santos (cf. idem, ibidem). Os Portugueses são de Portugal, mas também de muitos outros lugares. Por outro lado, sustenta E. Lourenço, os Portugueses nunca quiseram ser o Outro, pois ficam sempre muito portugueses. A própria ideia da vocação planetária e humanista é apenas mais um dos nossos mitos históricos. Significa isto que há, entre nós, um défice de diálogo efectivo, de problematização crítica, em favor dos consensos. Terá

\footnotetext{
${ }^{6}$ Cf. Memorial do Convento (1982) e História do Cerco de Lisboa (1989).

${ }^{7}$ Cf. A Jangada de Pedra (1986).

${ }^{8}$ Cf. O Ano da Morte de Ricardo Reis (1984).

${ }^{9}$ Cf. O Evangelho segundo Jesus Cristo (1991).

${ }^{10}$ Cf. Ensaio sobre a Cegueira (1996) ou A Caverna (2000).
} 
sido assim no tempo dos Descobrimentos e em tempos posteriores (o que não significa que não haja excepções, evidentemente). Quando a Europa começou o diálogo das culturas e das ideias, Portugal ausentou-se e, por isso, terá chegado atrasado à Europa, já no período pós-colonial. Mas, em contrapartida, criou um mundo de língua portuguesa imenso e plural. Por isso, dirá E. Lourenço que o maior mito português nem sequer é o do sebastianismo ou outro qualquer tema a que estamos a regressar constantemente, mas antes um simples Nome: Portugal.

Resta saber que ideais mobilizadores, em termos culturais e políticos, serão os escolhidos para Portugal e para as outras nacionalidades da Comunidade Europeia (alargada agora 27 membros), neste período de transformações conturbadas e perturbantes em que vivemos. E também conviria atentar no papel que os saberes relacionados com a cultura das humanidades virá (ou não) a desempenhar no âmbito desses mesmos ideais ou projectos nacionais e comunitários (C.E. e C.P.L.P.). 


\section{Bibliografia}

ÁRIAS, Martín e HADIS, Martín (org., pesquisa e notas) (2002). Curso de Literatura Inglesa - Jorge Luís Borges. Trad. de Eduardo Brandão. São Paulo: Martins Fontes.

BuEsCU, Maria Leonor Carvalhão (1992). Literatura Portuguesa Clássica. Lisboa: Universidade Aberta.

Caminha, Pêro Vaz de (1967). Carta de... In Obras Completas de Jaime Cortesão. Lisboa: Portugália Editora.

CAMÕES, Luís Vaz de (s/d). Os Lusíadas. Edição organizada por Emanuel Paulo Ramos. Porto: Porto Editora.

Catroga, Fernando e Carvalho, Paulo Archer de (1996). Sociedade e Cultura Portuguesas II. Lisboa: Universidade Aberta.

CoelHo, Jacinto do Prado (1983). Originalidade da Literatura Portuguesa. Lisboa: I.C.L.P. - Biblioteca Breve.

CoelHo, Jacinto do Prado (dir.) (1997). Dicionário de Literatura. Porto: Mário Figueirinhas Editor.

GÂNDAvo, Pêro de Magalhães (1984). História da Província Santa Cruz a que Vulgarmente Chamamos Brasil. Edição fac-similada da edição de 1576 e com nota prévia de Francisco Leite de FARIA. Lisboa: Biblioteca Nacional.

LouRENÇO, Eduardo (1978). O Labirinto da Saudade - Psicanálise Mítica do Destino Português. Lisboa: Publicações D. Quixote.

PAscoAIS, Teixeira de (1991). Arte de Ser Português. Lisboa: Assírio e Alvim.

PessoA, Fernando (1986). Textos de Intervenção Social e Cultural. Mem Martins: Publicações Europa-América.

PINTO, Fernam Mendez (1995). Peregrinaçam... Edição fac-similada da edição de 1614 e com apresentação de José Manuel GARCIA. Maia: Castoliva Editora Limitada.

SILVA, Augusto Santos e JORGE, Vítor Oliveira (orgs.) (1993). Existe uma Cultura Portuguesa?. Porto: Edições Afrontamento. 